\section{El GCPHE invita a reflexionar sobre la integración de la arquitectura contemporánea en sus conjuntos históricos}

La Comisión de Urbanismo del Grupo de Ciudades Patrimonio de la Humanidad de España (GCPHE) decidió abordar la complicada y polémica relación entre la arquitectura contemporánea y los conjuntos históricos protegidos. Para este cometido organizó un concurso para la elaboración de un estudio que analizara la controvertida relación entre arquitectura contemporánea y las trece ciudades que engrosan el GCPHE, siendo presentado en unas jornadas organizadas en Córdoba el pasado mes de noviembre. El encuentro tuvo un carácter multidisciplinar, participando en el mismo más de cincuenta profesionales.

La propuesta ganadora del concurso fue la del equipo Me(c)sa, bajo la dirección de Francisco Pol Méndez y Asunción Rodríguez Montejano, cuyo resultado es el trabajo Estrategias para la incorporación de la arquitectura contemporánea en las ciudades Patrimonio de la Humanidad de España. Este documento fue presentado y debatido en Córdoba en el ámbito de las Jornadas que tuvieron lugar durante los dias 5, 6 y 7 de noviembre de 2009, realizadas con el patrocinio del Ministerio de Cultura y la colaboración de la Gerencia de Urbanismo del Ayuntamiento de Córdoba y organizadas por el GCPHE. Esta asociación está integrada por municipios españoles con conjuntos históricos inscritos en la lista de Patrimonio Mundial de la UNESCO: Alcalá de Henares, Ávila, Cáceres, Córdoba, Cuenca, Ibiza, Mérida, Salamanca, San Cristóbal de La Laguna, Santiago de Compostela, Segovia, Tarragona y Toledo.

El objetivo de las jornadas es extraer una serie de conclusiones que pudiesen servir de guía y apoyo a técnicos y políticos gestores, sobre cómo fomentar la incorporación de la arquitectura contemporánea de calidad en nuestras ciudades, respaldada por un importante cuadro de técnicos y teóricos.

Para ello las jornadas se estructuraron en dos bloques; el primero de ellos se orga-

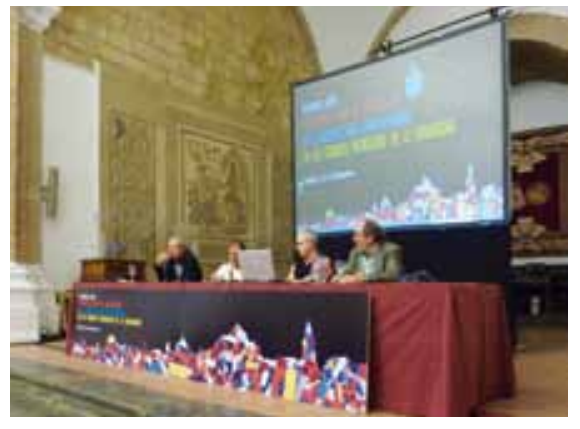

Una de las conferencias del encuentro. Foto: Pedro Caro

nizó a puerta cerrada y consistió en ocho mesas de trabajo temáticas, con un mínimo de seis personas en cada una de ellas, coordinadas por técnicos de las ciudades del grupo. En el segundo bloque, abierto al público, se impartieron una serie de conferencias de arquitectos de prestigio. En ellas participaron José Ignacio Linazasoro, Carlos Riaño, Andrés Perea, José A. Martínez Lapeña, José González Gallegos, Damián Quero Castanys, Antón Capitel y Carlos Garcia Vázquez y fueron presentadas por Juan Ojeda Rivera y Gaia Readelli.

Las conclusiones se pueden resumir en los siguientes puntos:

- El momento actual debe reivindicar el derecho a su propia historia.

- El planeamiento debe partir de un enfoque paisajístico de la ciudad. Se debe prever la redacción de planes directores específicos y diferenciar entre la arquitectura singular y la de escala menor, que es la que conforma la mayor parte del parcelario de los conjuntos históricos.

- Las actuaciones relevantes deben ir acompañadas de un Estudio de Impacto y deben ser el resultado de un concurso de arquitectura, dada la vulnerabilidad de estos entornos.

- La arquitectura debe dar respuesta a las nuevas realidades y demandas sociales, siempre respetando el valor patrimonial del lugar donde se inserta.

- Los equipamientos deben ser el resultado de una reflexión global sobre la ciudad y deben incluir un programa de gestión.

- La sostenibilidad y el ahorro energético son factores determinantes.

- El espacio público debe ser objeto de una propuesta global desarrollada en un Plan Director, en el diseño deben prevalecer los mismos criterios de autenticidad que en la edificación.

- Debe prestarse especial atención a la accesibilidad, apostando por diseños que la primen frente a tratamientos superficiales incómodos supuestamente históricos.

- La mejora de la movilidad y la supresión de la contaminación visual son factores determinantes en la calidad urbana.

- Es necesario estar atento a nuevos usos sociales del espacio público y a las nuevas tecnologías.

- El turismo debe tener un carácter sostenible y no debe tratar la ciudad como un producto de consumo. Hay que evitar la tematización y la escenografía.

- Se deben arbitrar mecanismos que fomenten la participación ciudadana mediante la difusión y la implicación social.

El carácter complejo de la ciudad histórica requiere soluciones imaginativas y el compromiso de todos los estamentos que intervienen en estos entornos. La gestión debe ir encaminada a evitar la improvisación y debe estar coordinada por equipos multidisciplinares.

\section{Pedro Caro}

Secretario de la Comisión de Urbanismo del GCPHE

Director de las Jornadas 